\title{
Replicase-Derived Resistance Against Pea early browning virus in Nicotiana benthamiana Is an Unstable Resistance Based upon Posttranscriptional Gene Silencing
}

\author{
Tom van den Boogaart, Fuijang Wen, Jeffrey W. Davies, and George P. Lomonossoff \\ John Innes Centre, Norwich Research Park, Norwich NR4 7UH, U.K. \\ Accepted 25 October 2000.
}

\begin{abstract}
Virus resistance in Nicotiana benthamiana plants containing a translatable Pea early browning virus (PEBV) 54K sequence from the $201 \mathrm{~K}$ replicase gene has been reported previously. Resistant plants contain multiple transgene copies divided between two loci. Analysis of a genetic series containing the two loci in separate homozygous or heterozygous condition suggest that only one of the loci is necessary to induce the resistance. The resistance observed in $R 2$ and $R 3$ generations of lines containing both transgene loci in homozygous condition became less consistent in $\mathbf{R 4}$ and $\mathbf{R 5}$ generations. This inversely correlated with steady-state transgene transcript levels of the segregating populations. The use of recombinant Potato virus $X$ vectors carrying PEBV 54K sequences showed that the resistance is based upon posttranscriptional gene silencing, is non-strand specific, and recognizes $3^{\prime}$ located sequences within the PEBV 54K sequence.
\end{abstract}

Pathogen-derived resistance, as formulated by Sanford and Johnston (1985), predicts that the expression of pathogenderived products in a host can disrupt essential pathogenic processes and result in resistance to the pathogen (Baulcombe 1996; Fitchen and Beachy 1993; Lomonossoff 1995). Generally, two types of resistance can be distinguished (Baulcombe 1996; Van den Boogaart et al. 1998), one that requires the presence of transgene-derived protein (Brederode et al. 1995; Lapidot et al. 1993; Powell-Abel et al. 1986) and the other requiring the presence of transgene-specific RNA (De Haan et al. 1992; Lindbo and Dougherty 1992; Van der Vlugt et al. 1992). This second type of resistance, called "RNA-mediated resistance," is similar to a more general mechanism, "posttranscriptional gene silencing" (PTGS) (English et al. 1996; Mueller et al. 1995).

In 1992, pathogen-derived resistance was obtained for the Pea early browning virus (PEBV) isolate SP5 (MacFarlane and Davies 1992). PEBV (Boulton 1996) belongs to the To-

Corresponding author: T. van den Boogaart;

Telephone: +44 1603450540

E-mail: tom.van-den-boogaart@bbsrc.ac.uk

Current address of F. Wen: Shandong Agricultural University, 61 Daizong St., Taian, Shandong Province, 271018 PR, China. braviridae spp., an important family of plant pathogens typified by Tobacco rattle virus (TRV). The genome of tobraviruses is divided in two single-stranded, positive-sense RNA molecules, each encapsidated separately by the coat protein. RNA-1 of PEBV encodes two replicase proteins, the larger (201K) being expressed by readthrough of the opal (UGA) termination codon at the end of the smaller protein $(141 \mathrm{~K})$ (MacFarlane et al. 1989). In an attempt to generate resistance against PEBV isolate SP5, MacFarlane and Davies (1992) transformed Nicotiana benthamiana plants with the readthrough portion of the replicase genes, or the " $54 \mathrm{~K}$ sequence." Southern blot analysis revealed a complex integration pattern with multiple copies of the $54 \mathrm{~K}$ sequence present. Susceptible plants within a segregating R2 population had a higher $54 \mathrm{~K}$ transcript level compared with resistant plants and were missing a particular integrated T-DNA. Resistant plants showed a high resistance phenotype, or immunity. The resistance was effective against an uncharacterized isolate of PEBV and Broad bean yellow band virus (a serotype of PEBV) (Robinson and Harrison 1985) but not against TRV or Pepper ringspot virus (the third member of the tobraviruses). Although the sequence similarities between these isolates and SP5 are unknown, the former characteristics are often associated with RNA-mediated resistance (Baulcombe 1996; Van den Boogaart et al. 1998). A modified form of the $54 \mathrm{~K}$ sequence, resulting in a prematurely terminated $54 \mathrm{~K}$ protein, was unable to induce resistance, leading to the suggestion that the protein rather than the RNA could be responsible for the resistance (MacFarlane and Davies 1992).

To analyze the mechanism(s) underlying the resistance to PEBV in plants transgenic for the PEBV 54K sequence, the resistance was followed over several generations and combined with DNA and RNA analysis. Such approaches have been used to characterize RNA-mediated resistance or PTGS (Dougherty et al. 1994; Goodwin et al. 1996; Smith et al. 1994). A series of progeny lines was generated by selffertilizing the original transformant or by crossing with nontransformed plants. Genetic analysis revealed that resistance segregated with a complex locus recognizes a minimum sequence of the $3^{\prime}$ end of the $54 \mathrm{~K}$ sequence for the incoming virus and operates by a PTGS mechanism. Furthermore, detailed analysis of the resistance over four generations revealed that the resistance occasionally breaks down. 


\section{RESULTS}

\section{T-DNA analysis of transgenic $N$. benthamiana} containing a translatable PEBV 54K sequence.

Transgenic $N$. benthamiana line pRok54.3.2, as described by MacFarlane and Davies (1992), served as the starting material for subsequent studies. This line was transformed with the readthrough portion of the replicase genes from PEBV, the 54K sequence, inserted between a Cauliflower mosaic virus (CaMV) $35 \mathrm{~S}$ promoter and a NOS terminator. After inoculation of segregating R2 plants (R0 being the primary transformant), the resistance against PEBV appeared to segregate with a particular integrated copy of the transgene (MacFarlane and Davies 1992).

To investigate these correlations and the underlying mechanism(s), R2-segregating plants were analyzed for their T-DNA organization and tested for their resistance to PEBV by following symptom development and using an enzyme-linked immunosorbent assay (ELISA) to detect the viral coat protein. This enabled the selection of individual susceptible and resistant plants, which were used to generate homozygous lines for further characterization of the resistance.

Genomic DNA was isolated from individual R2 plants, digested with HindIII (there is one site within the transferred DNA), and probed for the complete PEBV 54K sequence (Fig. 1). Two patterns of hybridization could be distinguished. DNA extracted from plants $1,18,19$, and 20 gave only a single band of approximately $4.9 \mathrm{~kb}$, whereas DNA from plants $4,5,7,8,9,10,11,12,13$, and 17 gave three bands, one of which was apparently the same size as the single band found in plants $1,18,19$, and 20 . The segregation pattern of the transgenes indicates that they are dispersed between two loci (presumably located on two different chromosomes): locus A, which gives rise to the $4.9-\mathrm{kb}$ band seen in all plants, and locus $B$, which produces two additional bands ( 3.7 and $5.5 \mathrm{~kb}$ ) found in plants $4,5,7,8,9,10,11,12,13$, and 17. Cosegregation of the 3.7- and 5.5-kb bands has been observed consistently in R3 and R4 generations (results not shown), supporting the notion that these two bands come from the same locus. The observed pattern suggests that the R1 parental plant, from which the analyzed R2 plants are derived, was homozygous for locus A and heterozygous for locus B.

All ten plants giving rise to three bands were immune to infection by PEBV, whereas three out of the four plants containing only the single band were susceptible. This suggests that resistance generally correlates with the presence of three bands. The exception to this is plant 1 , which gave only a single hybridizing band but appeared to be resistant. There are two possible explanations for this apparent discrepancy: plant 1 is genuinely different from the other single-band plants (18, $19,20)$ or somehow escaped infection during the inoculation process and was actually susceptible. The latter explanation is plausible because a small percentage of such escapes is observed consistently, even with nontransformed $N$. benthamiana.

To determine the influence of the integration pattern on resistance and to investigate whether plant 1 is genuinely different from the other plants that only contain locus A, plants 1 (pRok54.3.2.1), 10 (pRok54.3.2.10), and 19 (pRok54.3.2.19) were investigated. These three plants constitute the representative genotypes-phenotype combinations. Southern blot analysis and segregation of kanamycin resistance (the $54 \mathrm{~K}$ sequence is adjacent to the NPTII gene, resulting in cosegregation) of progeny plants from backcrossings with nontransgenic $N$. benthamiana, showed that plants 1 and 19 were homozygous for locus A, whereas plant 10 was homozygous for locus A and locus B (results not shown).

Pooled genomic DNA from R3 progeny, derived from plant 1,10 , and 19 (obtained by selfing), was digested with restriction endonuclease HindIII, EcoRI (both cleave only once within the T-DNA), or a combination, and probed for the complete PEBV 54K sequence (Fig. 2). The progeny of plants 1 and 19 have the same integration pattern, confirming the obtained hybridization pattern for the R2 generation (Fig. 1B). The single band obtained for HindIII and EcoRI digests suggests a single $54 \mathrm{~K}$ transgene at locus A. Analysis of locus B in the progeny of plant 10 suggests three possibilities: i) three transgene copies are arranged as head-to-head-tail-to-tail repeats (Fig. 2C); ii) a tail-to-tail repeat with $3.5 \mathrm{~kb}$ of intervening DNA (plant DNA or vector DNA not containing the $54 \mathrm{~K}$ sequence) containing a HindIII site after 750 nucleotides (nt); iii) a head-to-head repeat with $5.2 \mathrm{~kb}$ of intervening DNA containing an EcoRI site after 250 nt. With the use of a different enzyme $(K p n \mathrm{I})$, two bands of 3 and $5 \mathrm{~kb}$ were obtained (results not shown), strongly supporting the first option of transgene integration. No large deletions for the promotertransgene-terminator region were observed (as illustrated by the HindIII +EcoRI digest), suggesting that the promotertransgene-terminator cassette is integrated correctly into the plant genome, although small aberrations cannot be excluded.

A

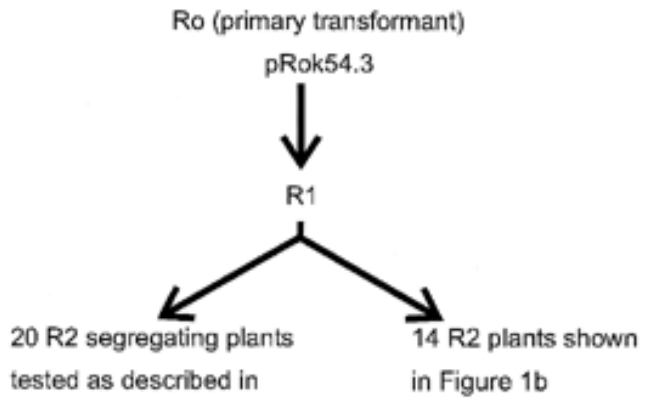

MacFarlane and Davies (1992)

B

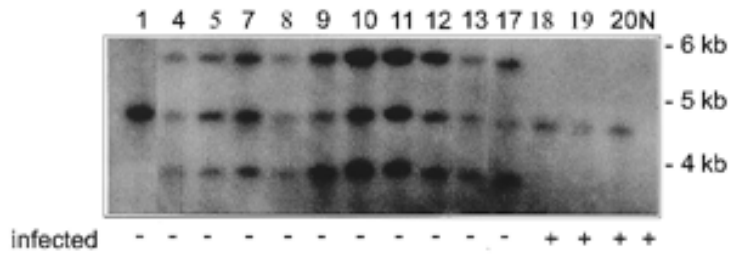

Fig. 1. T-DNA analysis and the correlation with resistance against $P e a$ early browning virus isolate SP5. A, Origin of the different plants tested (described here and in MacFarlane and Davies 1992). B, Genomic DNA isolated from transgenic R2 plants or nontransformed Nicotiana benthamiana $(\mathrm{N})$, digested with HindIII, and probed for the $54 \mathrm{~K}$ sequence. Numbers represent individual R2 kanamycin-resistant plants. Presence (+) or absence (-) of PEBV SP5, as determined by enzymelinked immunosorbent assay and symptom scoring, is indicated. 


\section{PEBV 54K-mediated resistance is unstable over multiple generations.}

To gain insights into the relation among transgene dosage, transcript levels, and resistance, homozygous and heterozygous progeny from plants 1,10 , and 19 were analyzed over a number of generations. As observed in the R2 generation, plants containing only locus A (plants 1 and 19, in homozygous or heterozygous condition) were generally susceptible, although there were a small number of exceptions observed in all generations (the inoculation efficiency was 97 to $100 \%$ ) (Fig. 3A). The similarity in resistance and the identical pattern in Southern blots for plants 1 and 19 suggests that the presence of the transgene in plant 1 does not confirm resistance. This supports the earlier suggestion that the resistance observed for plant 1 in the R2 generation is most likely an es-

A

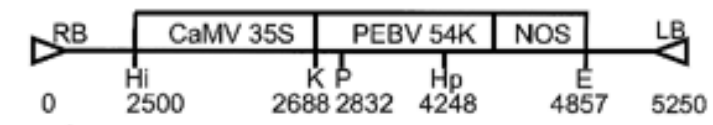

B
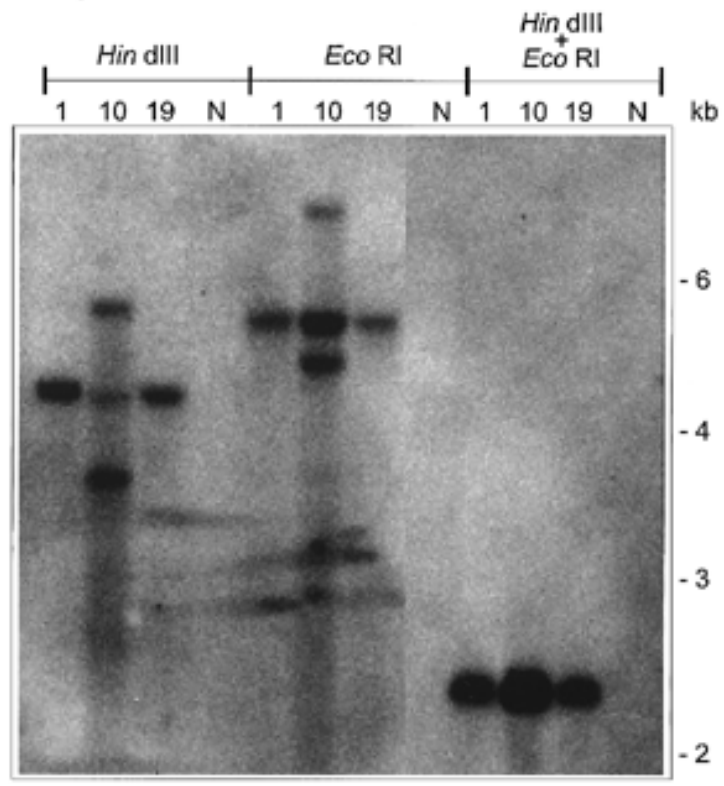

C

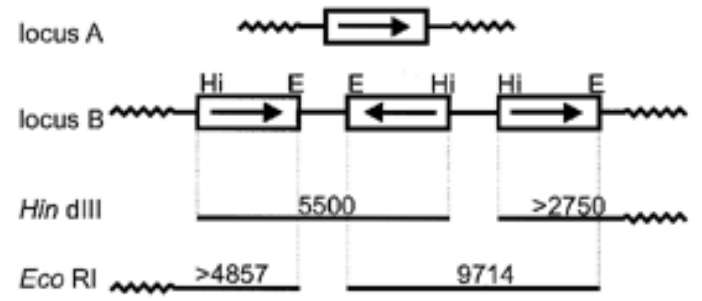

Fig. 2. T-DNA organization in pRok54.3.2. A, Physical map of the TDNA construct used to generate transgenic Nicotiana benthamiana $\mathrm{RB}=$ right border; $\mathrm{LB}=$ left border; CaMV35S = CaMV35S promoter; $\mathrm{NOS}=\mathrm{NOS} 3^{\prime}$ polyadenylation region; $\mathrm{Hi}=\operatorname{HindIII} ; \mathrm{K}=K p n \mathrm{I}$; $\mathrm{P}=P v u \mathrm{II} ; \mathrm{Hp}=H p a \mathrm{II} ; \mathrm{E}=$ restriction endonuclease designation (EcoRI). B, Southern blot analysis of pRok54.3.2.1, pRok54.3.2.10, and pRok54.3.2.19 ( $\mathrm{N}$ is nontransgenic $N$. benthamiana). Genomic DNA was isolated from R3 homozygous plants; digested with HindIII, EcoRI, or both; and probed with a complete PEBV 54K DNA probe for the 54K sequence. C, Deduced organization of the T-DNA loci in pRok54.3.2.10. Potential products for HindIII and EcoRI digest are indicated. Arrow shows the orientation of the transgene; squiggly line indicates intervening DNA (plant or vector). Note that $\mathbf{A}$ and $\mathbf{C}$ are not drawn to scale. cape from inoculation (although it should be noted that PTGS in plant 1 cannot be excluded, particularly because results presented later in this paper suggest that factors other than transgene integration influence PTGS).

R3 progeny from plant 10 showed a high degree of resistance to PEBV infection in a heterozygous (20\% susceptibility) and a homozygous state, with only one plant infected out of 50 inoculated ( $2 \%$ susceptibility). Southern blot analysis demonstrated that this infected plant had the same T-DNA organization as the parental plant. Virus isolated from this

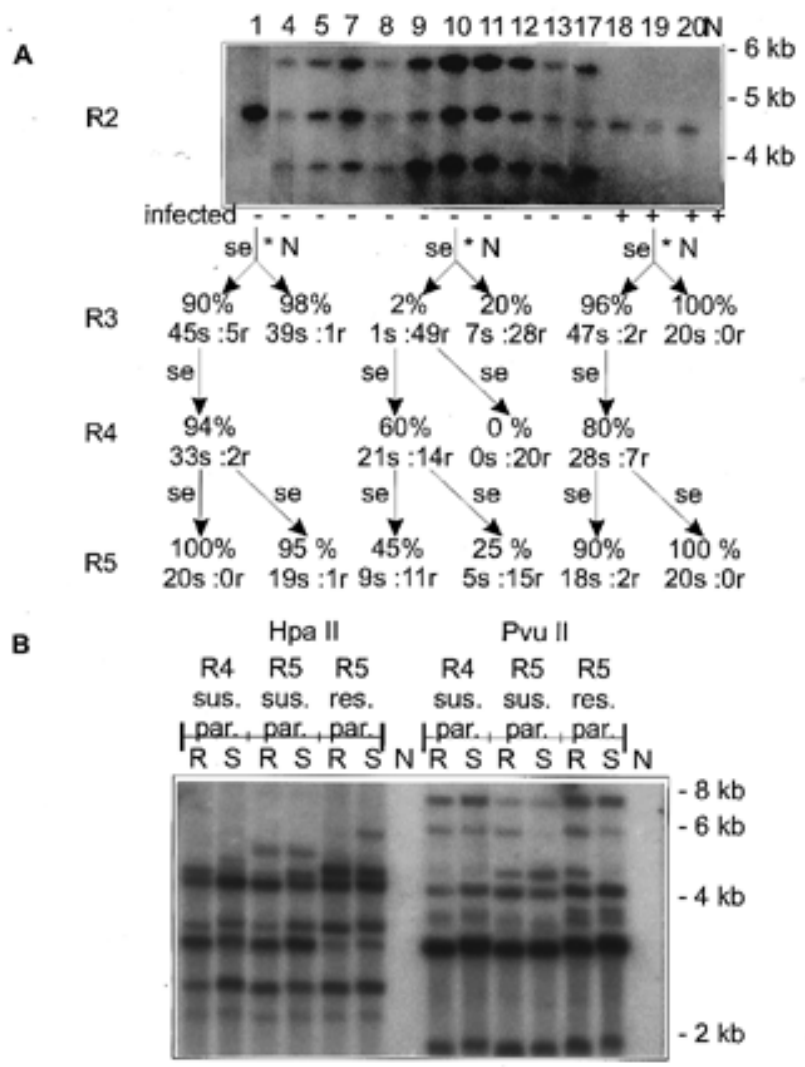

C

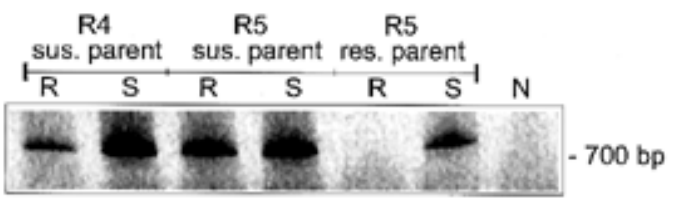

Fig. 3. Inheritance of 54K-mediated resistance in R2, R3, and R4 progeny of $54 \mathrm{~K}$ transgenic plants. A, pRok54.3.2.1, pRok54.3.2.10, and pRok54.3.2.19 were used for self-fertilization and crossings with nontransgenic Nicotiana benthamiana. The number of plants that became infected is shown as percentages (actual number is given below the percentage number). Arrow indicates the parental plant. Below "s" indicates a susceptible plant was used to create progeny; below "r," a resistant plant was used to create progeny. B, Methylation analysis of pRok54.3.2.10 segregating R4 and R5 populations. Genomic DNA was digested with $H p a I I$ and $P v u I I$ and probed for the $54 \mathrm{~K}$ sequence. C, Transcript analysis of segregating plants of pRok54.3.2.10 R4 (from a susceptible parent) and R5 generations. Total RNA was isolated, followed by production of cDNA of polyadenylated transcripts. RACE polymerase chain reaction was performed followed by Southern blot analysis of amplified 54K cDNAs. sus. par. = susceptible parent; res. par. $=$ resistant parent; $\mathrm{s}$ or $\mathrm{S}=$ susceptible; $\mathrm{se}=$ selfed; $\mathrm{r}$ or $\mathrm{R}=$ resistant; $\mathrm{N}=$ nontransgenic $N$. benthamiana $; * \mathrm{~N}=$ crossed with nontransgenic $N$. benthamiana. 
plant was unable to break through the resistance of other homozygous plant 10 plants, ruling out the possibility that the infected plant contained a resistance-breaking virus variant (results not shown). Progeny plants from this single, susceptible plant showed an enhanced susceptibility $(60 \%)$ in the R4 generation, whereas progeny from a resistant R3 plant remained completely resistant. The segregation resistancesusceptibility was transmitted to the R5 generation by susceptible (progeny $45 \%$ susceptible) and resistant (progeny $25 \%$ susceptible) R4 parents.

To determine whether the segregation observed in the R5 and R4 (from a susceptible parent) in plant 10 correlated with the methylation pattern, genomic DNA was digested with $P v u I I$, located in the $5^{\prime}$ part of the PEBV 54K sequence (Fig. 2A) and HpaII, located in the $3^{\prime}$ part of the PEBV $54 \mathrm{~K}$ sequence (Fig. 2A), and probed for the $54 \mathrm{~K}$ sequence. $P v u \mathrm{II}$ and HpaII are sensitive to symmetrical cytosine methylation. A typical Southern blot is shown in Figure 3B. Analysis of genomic DNA digested with HpaII and PvuII followed by probing for the $54 \mathrm{~K}$ sequence showed differences when resistant plants were compared with susceptible plants within the different populations. When plants were compared over several generations by parental origins, however, no consistent differences could be correlated with the resistance.

Leaf tissue of the same developmental age as that of the inoculated tissue was used for transcript analysis. Attempts to visualize $54 \mathrm{~K}$ transcripts by Northern blot analysis of total RNA or poly(A)+ mRNA were unsuccessful, although transcripts could be detected after cDNA of polyadenylated transcripts was subjected to polymerase chain reaction (PCR) followed by Southern blot analysis (RACE PCR). Transcripts were detected in all plants except resistant R5 plants, and an inverse correlation was observed between $54 \mathrm{~K}$ transcript levels and resistance (Fig. 3C). This was confirmed by a TaqMan assay (PE Biosystems, Norwalk, CT, U.S.A.) (results not shown). The observation of a higher transgene transcript level in susceptible plants is consistent with resistance operating through PTGS.

\section{PEBV 54K-mediated resistance does not require locus A.}

To determine whether locus $\mathrm{A}$ is required to establish the resistance, plants containing only locus B were generated by backcrossing (selected by Southern blot analysis) (Fig. 4) and subsequent selfing of heterozygous plant 10 . Lines that were either homozygous or heterozygous for locus B, termed 1W5 homozygous or 1W5 heterozygous, respectively, were selected on the basis of kanamycin segregation data. When inoculated with PEBV, homozygous plants showed 6\% susceptibility ( 1 out of 16 plants became infected), whereas heterozygous plants showed 5\% susceptibility ( 1 out of 19 plants became infected). Thus plants homozygous for locus B showed resistance equivalent to homozygous plants containing locus A and B (Fig. 3).

Previous analysis with RACE PCR (MacFarlane and Davies 1992) suggested an inverse correlation between resistance and transgene transcript levels, which is typical of RNA-mediated resistance. To confirm and investigate this inverse relationship, RACE PCR was performed on total RNA from plants 1, 10, 19, and 1W5 in homozygous condition. Transgene transcripts could be detected in plants 1 and 19 (Fig. 5), which confirmed the inverse relation between trans- gene transcript levels and resistance. The two bands observed for plants 1 and 19 (Fig. 5) correspond to single- and doublestranded DNA. Lines 10 and 1W5 were resistant and showed undetectable levels of transcripts, although transcripts were detected in plant 10 with RACE PCR (Fig. 3C) and TaqMan (results not shown).

The T-DNA organization of plant 10 is the sum of plants 1 (or 19) and 1W5. If transgene silencing was not occurring, one would expect the transgene transcript levels to be the sum of the two lines. Clearly, transcript levels in plant 10 are much lower.

\section{Resistance in 54K transgenic plants and PTGS.}

Genetic analysis of lines transgenic for the PEBV $54 \mathrm{~K}$ sequence indicate that resistance to PEBV operates through a silencing mechanism. To rule out the possibility that protein may be involved, two types of constructs were made and inserted into a PVX vector (Baulcombe et al. 1995). The first type contained the full-length PEBV 54K sequence, either in sense or antisense orientation. To determine whether the resistance recognizes specific sequences or merely a specific length of homology, a second range of constructs was produced. These constructs contained sequences from the $5^{\prime}$ or $3^{\prime}$ ends of the $54 \mathrm{~K}$ sequence, with identical sizes. If the resistance develops on the basis of interference with protein products of PEBV, the mechanism would be unable to interfere with the infection of a heterologous virus, even if it carried the sequence used to create the resistance.

Infectious transcripts were inoculated onto the three homozygous representative lines of plant 1 (locus A), 1W5 (locus

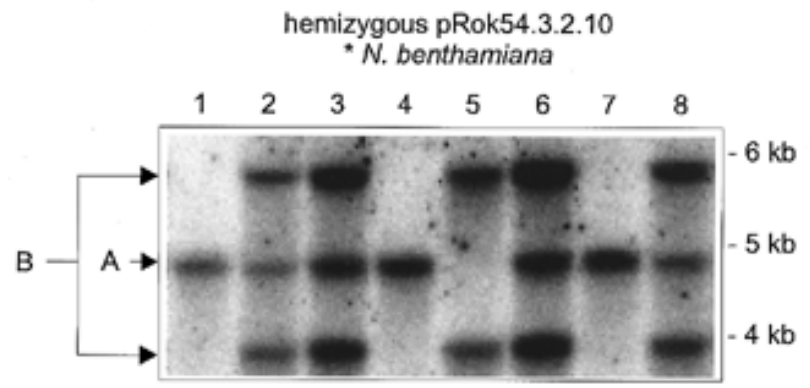

Fig. 4. T-DNA organization of backcross progeny of heterozygous pRok54.3.2.10 with nontransgenic Nicotiana benthamiana. Genomic DNA was digested with HindIII and probed for the 54K sequence. Eight lines are shown, of which pRok54.3.1W5 (lane 5) was used in subsequent experiments. Arrows indicate the bands associated with locus A and $B$.

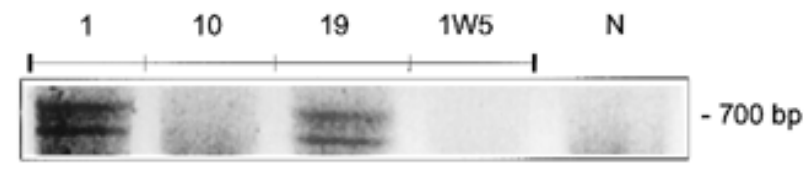

Fig. 5. Analysis of $54 \mathrm{~K}$ transcripts from representative $54 \mathrm{~K}$ transgenic lines. Total RNA was isolated from representative lines 30 days postgermination. RACE polymerase chain reaction was performed on cDNA of polyadenylated transcripts, followed by Southern analysis of amplified $54 \mathrm{~K}$ cDNAs. 1, 10, 19, 1W5 = pRok54.3.2.1, pRok54.3.2.10, pRok54.3.2.19, and pRok54.3.1W5, respectively; $\mathrm{N}=$ nontransgenic Nicotiana benthamiana. Two bands observed for pRok54.3.2.1 and pRok54.3.2.19 are single- and double-stranded DNA molecules (MacFarlane and Davies 1992). 
B), and 10 (locus A and B). After approximately 30 days postinoculation, total RNA was isolated from systemic leaves and followed by analysis of the $54 \mathrm{~K}$ sequence (transgenederived transcripts were below the detection limit of Northern blot analysis; results not shown). This confirmed the absence or presence of the PEBV sequences and showed that no wildtype infections resulting from recombination were scored as susceptible. All recombinant PVX constructs were able to infect homozygous plant 1 (Fig. 6).

The resistance in homozygous $1 \mathrm{~W} 5$ and $10 \mathrm{R} 3$ plants targeted the PVX containing the $54 \mathrm{~K}$ in the sense or antisense orientation (all of the transgenic lines tested were susceptible to wild-type PVX; results not shown). This strongly suggests that the resistance targets RNA rather than protein, which is consistent with the previous suggestion that the resistance develops on the basis of PTGS. Furthermore, there seems to be no strand-specificity, suggesting that the resistance mechanism targets the genomic "plus" strands as well as the complementary, or "minus," strands.

PVX containing the $54 \mathrm{~K}$ sequence derived from the $5^{\prime}$ part was able to replicate on homozygous plants 10 and 1W5, suggesting that these $54 \mathrm{~K}$ sequences were neither recognized nor targeted by the resistance mechanism. PVX containing 3'located sequences of the $54 \mathrm{~K}$ sequence was unable to replicate in homozygous plants 10 and $1 \mathrm{~W} 5$, demonstrating that these $54 \mathrm{~K}$ sequences were targeted by the resistance mechanism. The shortest $54 \mathrm{~K}$ sequence shown to confer resistance contained the $3^{\prime}$ terminal $370 \mathrm{nt}$, suggesting that the recognized sequence is located within this region. It should be noted. however, that this sequence was not very efficiently recognized in homozygous plant 1W5. This finding is similar to that obtained with other systems (English et al. 1996; Sijen et al. 1996). Because some of the constructs represented deletions of similar length on the $5^{\prime}$ or $3^{\prime}$ end, it is unlikely that targeting develops on the basis of recognition of the minimal length of the PEBV 54K sequence.

\section{DISCUSSION}

Previously it was shown that the resistance in pRok54.3.2 was highly effective and correlated with multiple T-DNA insertions and low levels of transgene-derived RNA (MacFarlane and Davies 1992). Detailed analysis in this study showed that the transgenes were divided between two loci, which was supported by Southern blot analysis over multiple generations. Locus A contained a single transgene copy, whereas locus B most likely contained three transgenes arranged in a head-to-head-tail-to-tail configuration.

The resistance observed in 54K-transgenic plants is induced only by locus $\mathrm{B}$, which displays a number of characteristics generally associated with PTGS. The first is that locus B can transinactivate locus A. Transgene transcript levels of locus A are much higher when locus B is absent compared with transgene transcript levels when locus B is present. Furthermore, the transgene integration structure of locus B is characteristic for PTGS. Locus B displays two transgene integration characteristics generally associated with PTGS. The first is a transgene copy number. There seems to be a general correlation between a transgene copy number (or transgene transcript levels) and silencing. In a study similar to the one described in this paper, a genetic series of plants containing transgenes divided among different loci showed that resistance correlated with copy number (Goodwin et al. 1996).

The second characteristic of locus B is the presence of inverted repeats. PTGS is often correlated with complex T-DNA integrations that frequently contain repeats (Cluster et al. 1996; Hamilton et al. 1998; Sijen et al. 1996; Stam et al. 1997; Stam et al. 1998). Indeed, Sijen et al. (1996) showed that transformation with a direct repeat of the cowpea mosaic virus movement protein increased the percentage of resistant plants

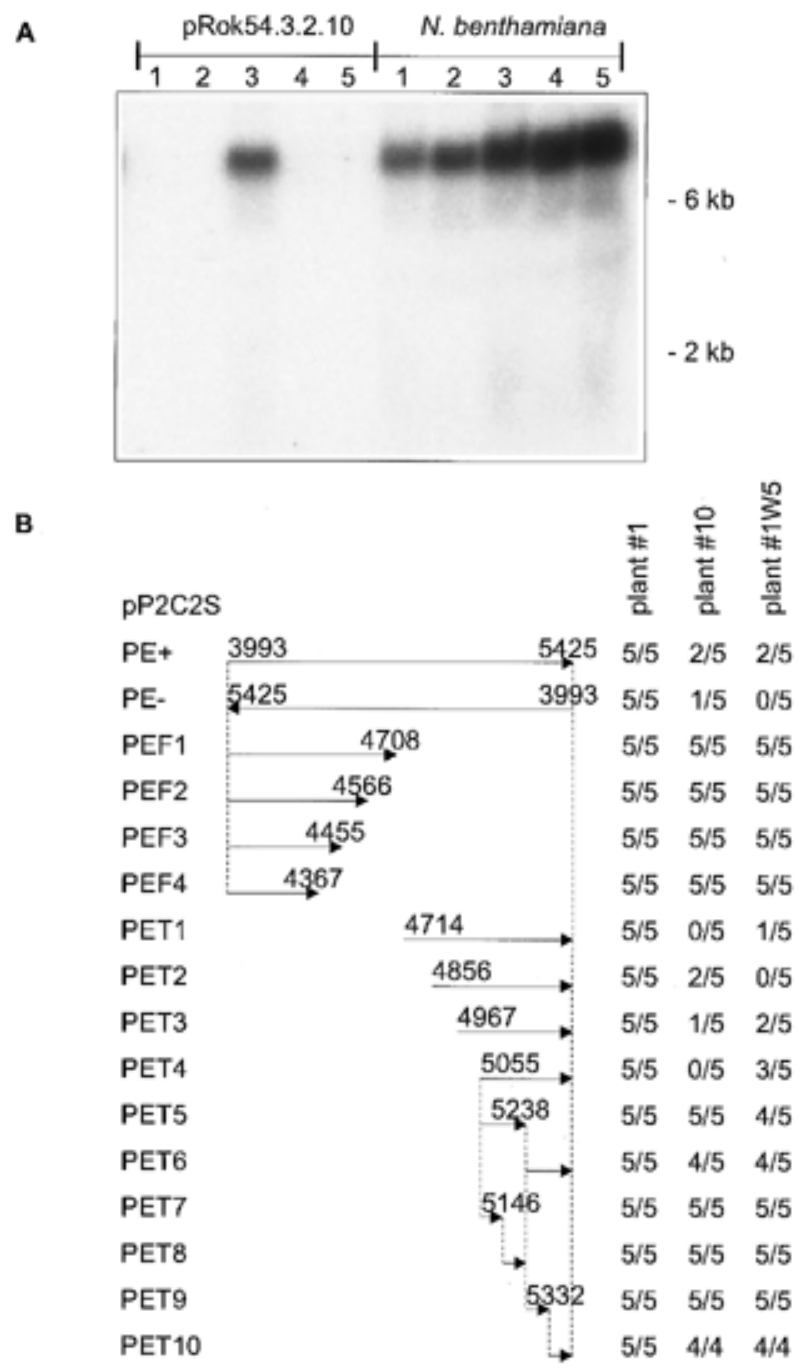

Fig. 6. Analysis of recombinant PVX accumulation. A, Northern blot analysis of the accumulation of pP2C2S-PET3 on nontransgenic Nicotiana benthamiana and pRok54.3.2.10. Although the accumulation of this construct is shown, all the constructs inoculated on all the lines and controls were analyzed in this manner. Plasmid pP2C2S is the wild-type PVX containing a duplicated coat protein promoter (Baulcombe et al. 1995). RNA was isolated from systemic leaves of inoculated plants and probed with a DNA probe for the $54 \mathrm{~K}$ sequence. B, Deletion analysis of the PEBV 54K sequence with a PVX vector. RNA was isolated from systemic leaves of nontransformed and transgenic $N$. benthamiana pRok54.3.2.1 and pRok54.3.2.10 (homozygous R3 generation plants). Arrow shows whether the insert is in the sense or antisense orientation. For the complete PEBV 54K sequence, the number of the first and last nucleotide is shown; for other constructs, either the last (PEF1) or first nucleotide (PET1) is shown. Values indicate the number of infected plants (as determined by Northern blot analysis) per total number of plants inoculated. 
to $60 \%$ compared to $20 \%$ for single-copy insertions. Hamilton et al. (1998) showed that $96 \%$ of plants transformed with an ACC oxidase gene containing two additional upstream inverted copies of its $5^{\prime}$ untranslated region showed gene silencing compared with $15 \%$ of plants without the repeat. Unfortunately, no conclusions can be drawn as to which of the two characteristics mentioned is responsible for the induction of resistance.

The characteristics of the resistance, immunity, strain specificity, and a low accumulation of transgene-derived RNA are characteristic of RNA-mediated resistance (Baulcombe 1996; Lomonossoff 1995; Van den Boogaart et al. 1998). In their initial report, MacFarlane and Davies (1992) suggested that the $54 \mathrm{~K}$ protein might mediate the resistance on the basis of the observation that modified forms of the $54 \mathrm{~K}$ sequence, resulting in a prematurely terminated $54 \mathrm{~K}$ protein, were unable to induce resistance. Only a low number of lines were tested, however, and plants transformed with an untranslatable version of the $54 \mathrm{~K}$ sequence were subsequently shown to be resistant (C. Wallis, G. P. Lomonossoff, and J. W. Davies, unpublished results).

The suggestion of an RNA-based mechanism also is supported by the finding that the resistance can act against PVX carrying PEBV 54K sequences. As was observed in other systems (English et al. 1996; Sijen et al. 1996), the target sequence is located in the $3^{\prime}$ part of the $54 \mathrm{~K}$ sequence and the recognition is not strand specific. Although the positive and negative strand of the $54 \mathrm{~K}$ sequence is produced during the replication process of PVX, the negative strand is generally regarded to be located in the replication complex and is thought to be inaccessible. The location of the target in the $3^{\prime}$ end is not a general rule, however, because multiple targets in the coding region have been observed for other systems (Jacobs et al. 1999; Marano and Baulcombe 1998). The resistance mechanism seems less effective against PVX containing the complete $54 \mathrm{~K}$ sequence or derivatives (ranging from zero out of five plants infected to two out of five plants infected) compared with resistance against PEBV SP5 (98\% resistance in the R3 generation). The reason for this is unclear, but it may reflect differences in the levels of virus accumulation or the site of replication between PEBV and PVX carrying PEBV sequences.

The resistance as observed in plants homozygous for both loci appears to be unstable. Although initially all plants showed the resistance (R3 and R4 plants from a resistant parent) in subsequent generations, the resistance started to segregate. Transgene analysis showed no obvious changes in transgene integration structure between generations. PTGS is reset during meiosis (Balandin and Castresana 1997; Dehio and Schell 1994) and should therefore display a stable phenotype over multiple generations. The reason behind the instability reported here is unclear, but not unprecedented. Instability was observed for plants containing a fragment of the Plum pox virus genome (Guo et al. 1998). Unfortunately, these transgenic plants were not examined by Southern blot analysis, so it is unclear how the T-DNA is integrated and whether fragments of the T-DNA are present at different loci. This could lead to complications because the zygosity was determined with kanamycin resistance data that does not necessarily correspond to the zygosity of the transgene. Additionally, the instability only concerned the R1 and R2 generation. R3 transgenic plants were consistent in their phenotype, which depended on the phenotype of the R2 parent (i.e., if the parent was resistant, the progeny would be resistant, and vice versa), in contrast with the instability in R5 54K-transgenic plants. The instability was related to levels of transgene transcripts as observed here, and resistant plants had a lower level of transgene mRNA as compared with susceptible plants. The low levels of RNA, however, are most likely a consequence of PTGS, so the underlying mechanism responsible for the segregation is unknown.

Instability of silencing also was detected in rice containing a bar transgene that encodes bialaphos herbicide resistance (Kumpatla and Hall 1998). Here the instability was correlated with extensive methylation in the promoter region. Smith et al. (1994) also showed that genetically identical plants can show differences in their phenotype. A double-haploid family of transgenic plants containing an untranslatable potato virus Y (PVY) coat protein showed differences in its response to PVY inoculation. This correlated to differences in steady-state mRNA levels and the methylation state of the transgene. PTGS is quite sensitive to changes in the rate of transcription (English and Baulcombe 1997) and, although differences in transgene steady-state transcript levels have been observed here, it is not clear whether they are a cause or a consequence of the segregation of the silencing. No correlation of methylation and resistance was found here, however, and only a low number of sites have been analyzed. Further instances of PTGS instability have since been reported (Tenllado and DíazRuíz 1999), stressing the need for multigeneration testing as has been stated by others (Kumpatla and Hall 1998).

\section{MATERIALS AND METHODS}

\section{Plant material and inoculation with PEBV.}

The transgenic $N$. benthamiana plant line pRok54.3.2 contains the readthrough portion or $54 \mathrm{~K}$ sequence of the replicase genes of PEBV (MacFarlane and Davies 1992). Nontransformed $N$. benthamiana plants were used as controls. Seed was sown and kept for approximately 4 weeks in the containment greenhouse under natural-light conditions before inoculations. Transgenic seed was germinated on MS medium (Murashige and Skoog 1962) containing $500 \mu \mathrm{g}$ of kanamycin per ml. After 2 weeks, the seedlings were transferred to soil and kept in the greenhouse for approximately 2 weeks before inoculations.

To generate heterozygous progeny from a homozygous parent, pollen from a transgenic homozygous parent was transferred to the stigma of nontransgenic $N$. benthamiana. Heterozygous seeds were then distinguished from nontransgenic seeds (resulting from self-pollination) by germination on MS medium containing $500 \mu \mathrm{g}$ of kanamycin per $\mathrm{ml}$, as described above.

PEBV isolate SP5 was propagated in and purified from the systemic host $N$. benthamiana, according to MacFarlane et al. (1989). The virus was resuspended in $30 \mathrm{mM}$ sodium phosphate buffer, $\mathrm{pH}$ 7.0. To challenge a plant, a leaf was mechanically inoculated with carborundum as an abrasive and PEBV at a concentration of approximately $1 \mathrm{mg}$ of inoculation buffer (20 mM phosphate, $\mathrm{pH} 7.2 ; 1 \mathrm{mM}$ EDTA) per ml. After inoculation with $20 \mu \mathrm{l}$ of virus suspension, the leaflet was rinsed with water. The inoculation efficiency with this method 
was always 97 to $100 \%$. Inocula also were applied to Chenopodium amaranticolor (a local lesion host for PEBV) to quantitate the infectivity of each inoculum. A concentration of $1 \mathrm{mg}$ of purified PEBV per $\mathrm{ml}$ corresponded to approximately 500 to 1,000 lesions per $20 \mu \mathrm{l}$ of inoculum per leaf.

\section{Detection of PEBV in infected tissue.}

Systemic leaves (younger than the inoculated leaf) were homogenized with a mechanical grinder in coating buffer (10 $\mathrm{mM} \mathrm{Na} \mathrm{CO}_{3}, 35 \mathrm{mM} \mathrm{NaHCO}$ ). The insoluble material was discarded following centrifugation $(5 \mathrm{~min}$ at full speed in a microfuge). The sample was applied to a Nunc-Immuno Plate MaxiSorp plate (Nalge Nunc International, Rochester, NY, U.S.A.), followed by a direct ELISA assay. Detection of viral coat protein was achieved by reaction with rabbit anti-PEBV serum followed by a goat anti-rabbit antibody conjugated with alkaline phosphatase with p-nitrophenylphosphate in diethanolamine buffer $(\mathrm{pH} 9.8)$ as a substrate. Plates were washed with phosphate buffered saline $(0.02 \mathrm{M}$ phosphate; $0.15 \mathrm{M}$ $\mathrm{NaCl} ; 0.003 \mathrm{M} \mathrm{KCl}, \mathrm{pH} 7.4)$ containing $0.05 \%$ Tween-20, and absorbance values were recorded at $405 \mathrm{~nm}$.

\section{Generation of recombinant PVX vectors and infection on plants.}

Constructs pP2C2S-PEF4, pP2C2S-PEF3, pP2C2S-PEF2, and pP2C2S-PEF1 (Fig. 6) were created by PCR with primers V1177 (sense nucleotides 211 to 231 in the $35 \mathrm{~S}$ promoter of pMon530) (Rogers et al. 1987) and V4097 (antisense nucleotides 388 to 366 in NOS terminator of pMon530) (Rogers et al. 1987) from template DNA pMon54.4367, pMon54.4455, pMon54.4566, and pMon54.4708, respectively (C. Wallis, G. P. Lomonossoff, and J. W. Davies, unpublished data).

Constructs pP2C2S-PET1 to PET4 (Fig. 6) were made by PCR with primers V4172 (sense nucleotides 4,714 to 4,746 of $54 \mathrm{~K}$ sequence), V4173 (sense nucleotides 4,856 to 4,888 of $54 \mathrm{~K}$ sequence), V4174 (sense nucleotides 4,967 to 4,999 of $54 \mathrm{~K}$ sequence) and V4175 (sense nucleotides 5,055 to 5,085 of $54 \mathrm{~K}$ sequence), respectively, in combination with V4171 (antisense nucleotide 5,425 to 5,401 of 54K sequence) from template pMon54.3 (a pMon530 transformation vector containing the complete PEBV 54K sequence) (C. Wallis, G. P. Lomonossoff, and J. W. Davies, unpublished data). Plasmid pP2C2S-PE+ was constructed with primers V4170 (sense nucleotides 3,993 to 4,025 of 54K sequence) and V4171 from template pMon54.3. Plasmids pP2C2S-PET5 and pP2C2SPET7 were constructed with PCR primers 991103 (antisense nucleotides 5,238 to 5,212 of $54 \mathrm{~K}$ sequence) and 991105 (antisense nucleotides 5,146 to 5,123 of $54 \mathrm{~K}$ sequence), respectively, in combination with primer V4175. Plasmids pP2C2S-PET6 and pP2C2S-PET9 were made by PCR primers V4171 and 991107, respectively (antisense nucleotides 5,332 to 5,312 of 54K sequence), in combination with 991104 (sense nucleotides 5,239 to 5,260 of $54 \mathrm{~K}$ sequence). pP2C2S-PET8 was constructed with PCR primers 991106 (sense nucleotides 5,147 to 5,167 of $54 \mathrm{~K}$ sequence) and 991103. pP2C2S-PET10 was made with PCR primers 991108 (sense nucleotides 5,333 to 5,352 of $54 \mathrm{~K}$ sequence) and V4171. Plasmids pP2C2SPET5 to PET10 were generated from template pMon54.3.

PCR reactions contained $5 \mathrm{ng}$ of template DNA; $10 \mathrm{mM}$ Tris- $\mathrm{HCl}, \mathrm{pH} 8.5 ; 50 \mathrm{mM} \mathrm{KCl} ; 1.5 \mathrm{mM} \mathrm{MgCl}_{2}$; five units of Taq polymerase; $250 \mu \mathrm{M}$ dATP, dCTP, dTTP, and dGTP; 2.5
$\mathrm{mM}$ primer (each); and volume was created with sterile water to $50 \mu \mathrm{l}$. Cycling conditions were $5 \mathrm{~min}$ at $94^{\circ} \mathrm{C}$, followed by 40 cycles of $1 \mathrm{~min}$ at $94^{\circ} \mathrm{C}, 1 \mathrm{~min}$ at $65^{\circ} \mathrm{C}$, and $2 \mathrm{~min}$ at $72^{\circ} \mathrm{C}$. The last cycle ended with a final extension of $10 \mathrm{~min}$ at $72^{\circ} \mathrm{C}$. The PCR program was run on an Omnigene thermal cycler (Hybaid Ltd., Ashford, Middlesex, U.K.).

For cloning, the PCR products were digested with ClaI (present in the 5' primers) and EcoRV (present in the $3^{\prime}$ primers) and ligated in a ClaI- and EcoRV-treated pP2C2S-vector (Baulcombe et al. 1995) with $1 \mathrm{U}$ of T4 DNA ligase in a ligase buffer + ATP for $14 \mathrm{~h}$ at $15^{\circ} \mathrm{C}$. The ligation mixture was used to transform Escherichia coli GM119, after which colonies were checked by PCR with primers V3793 (antisense nucleotide 5,917 pP2C2S) and V3794 (sense nucleotides 5,450 to $5,472 \mathrm{pP} 2 \mathrm{C} 2 \mathrm{~S}$ ) and restriction analysis.

In order to produce infectious transcripts, $25 \mu \mathrm{g}$ of template DNA was linearized with SpeI. In vitro transcription was performed as described by Chapman et al. (1992). One-fifth of the transcription reaction per plant was used for inoculation, as described earlier.

\section{Extraction of genomic DNA and Southern blot analysis.}

The isolation of genomic DNA was performed essentially as described by Dellaporte et al. (1985). PCR-generated PEBV 54K DNA fragments were labeled with ${ }^{32} \mathrm{P}-\mathrm{dCTP}$ and the Random Primers DNA Labeling System (Gibco BRL, Paisley, U.K.). Labeled DNA was separated from unincorporated nucleotides with a Nick column (Pharmacia, Milton Keynes, U.K.), according to the supplier's instructions.

For Southern blots, approximately $10 \mu \mathrm{g}$ of genomic DNA was digested overnight with $50 \mathrm{U}$ of the appropriate restriction enzyme, followed by transfer and hybridization as described in Sambrook et al. (1989).

\section{Extraction of RNA and Northern analysis.}

Total RNA was extracted with the RNeasy plant kit (Qiagen, Hilden, Germany), according to the instructions of the manufacturer. Poly $(\mathrm{A})+$ mRNA was isolated from total RNA with the Oligotex mRNA mini kit (Qiagen). For viral RNA detection, approximately $1 \mu \mathrm{g}$ of total RNA was loaded. RNA was run in a $1 \%$ formaldehyde agarose gel and transferred by capillary blotting to a Hybond NX nitrocellulose membrane (Boehringer Mannheim, Indianapolis, IN, U.S.A.), according to standard methods (Sambrook et al. 1989). Hybridization with a DNA probe, specific for the complete PEBV 54K sequence, was performed as described in Sambrook et al. (1989).

Transgene-derived transcripts of the PEBV 54K sequence were analyzed by 3' RACE PCR. Total RNA was isolated as described above and hybridized to the $3^{\prime}$ oligonucleotide V3469 (GACTCGAGTCGACATCGA( $\left.\mathrm{T}_{17}\right)$. cDNA was produced with Superscript reverse transcriptase (Gibco BRL), according to the manufacturer's instructions. Transcript cDNAs were detected with primers V4175 (CCATCGATAGCATTCTGCGGGAAGTTTTTG) and V3468 (GACTCGAGTCGACATCGA), followed by PCR as described before with an annealing temperature of $55^{\circ} \mathrm{C}$. PCR products were visualized by Southern blot analysis as described in Sambrook et al. (1989). Controls were included to ensure that no residual genomic DNA or viral RNA was amplified. 


\section{ACKNOWLEDGMENTS}

We thank D. Baulcombe for providing pP2C2S. All work was performed under MAFF license PHL11/2511(6/1998). T. van den Boogaart was supported by a grant from the John Innes Foundation.

\section{LITERATURE CITED}

Balandin, T., and Castresana, C. 1997. Silencing of a $\beta-1,3$-glucanase transgene is overcome during seed formation. Plant Mol. Biol. 34:125-137.

Baulcombe, D. C. 1996. Mechanisms of pathogen-derived resistance to viruses in transgenic plants. Plant Cell 8:1833-1844.

Baulcombe, D. C., Chapman, S. N., and Santa Cruz, S. 1995. Jellyfish green fluorescent protein as a reporter for virus infections. Plant $\mathrm{J}$. 7:1045-1053.

Boulton, R. E. 1996. Pea early browning virus. Plant Pathol. 45:13-28.

Brederode, F. T., Taschner, P. E. M., Posthumus, E., and Bol, J. F. 1995. Replicase-mediated resistance to Alfalfa mosaic virus. Virology 207:467-474

Chapman, S., Kavanagh, T., and Baulcombe, D. 1992. Potato virus X as a vector for gene expression in plants. Plant J. 2:549-557.

Cluster, P. D., O’Dell, M., Metzlaff, M., and Flavell, R. B. 1996. Details of T-DNA structural organisation from a transgenic Petunia population exhibiting PTGS. Plant Mol. Biol. 32:1197-1203.

De Haan, P., Gielen, J. J. L., Prins, M., Wijkamp, I. G., Van Schepen, A., Peters, D., Van Grinsven, M. Q. J. M., and Goldbach, R. 1992. Characterisation of RNA-mediated resistance to Tomato spotted wilt virus in transgenic tobacco plants. Bio/Technology 10:1133-1137.

Dehio, C., and Schell, J. 1994. Identification of plant genetic loci involved in a post-transcriptional mechanism for meiotically reversible transgene silencing. Proc. Natl. Acad. Sci. USA 91:5538-5542.

Dellaporte. S. L., Wood, J., and Hicks, J. B. 1985. Maize miniprep. In: Molecular Biology of Plants: A Laboratory Course Manual. R. Malmberg, J. Messing, and I. Sussex, eds. Cold Spring Harbor Laboratory, Cold Spring Harbor, NY, U.S.A.

Dougherty, W. G., Lindbo, J. A., Smith, H. A., Parks, T. D., Swaney, S., and Proebsting, W. M. 1994. RNA-mediated virus resistance in transgenic plants: Exploitation of a cellular pathway possibly involved in RNA degradation. Mol. Plant-Microbe Interact. 7:544-552.

English, J. J., and Baulcombe, D. C. 1997. The influence of small changes in transgene transcription on homology-dependent virus resistance and gene silencing. Plant J. 12:1311-1318.

English, J. J., Mueller, E., and Baulcombe, D. C. 1996. Suppression of virus accumulation in transgenic plants exhibiting silencing of nuclear genes. Plant Cell 8:179-188.

Fitchen, J. H., and Beachy, R. N. 1993. Genetically engineered protection against viruses in transgenic plants. Annu. Rev. Microbiol. 47:739-763.

Goodwin, J., Chapman, K., Swaney, S., Parks, T. D., Wernsman, E. A., and Dougherty, W. G. 1996. Genetic and biochemical dissection of transgenic RNA-mediated resistance. Plant Cell 8:95-105.

Guo, H. S., Cervera, M. T., and García, J. A. 1998. Plum pox potyvirus resistance associated to transgene silencing that can be stabilized after different number of plant generations. Gene 206:263-272.

Hamilton, A. J., Brown, S., Yuanhai, H., Ishizuka, M., Lowe, A., Solis, A. G. A., and Grierson, D. 1998. A transgene with repeated DNA causes high frequency, post-transcriptional suppression of ACCoxidase gene expression in tomato. Plant J. 15:737-746.

Jacobs, J. J. M. R., Sanders, M., Bots, M., Andriessen, M., Van Eldik, G. J., Litière, K., Montagu, M. V., and Cornelissen, M. 1999. Sequences throughout the basic $\beta$-1,3-glucanase mRNA coding region are targets for homology dependent post-transcriptional gene silencing. Plant $\mathbf{J}$. 20:143-152.

Kumpatla, S. P., and Hall, T. C. 1998. Recurrent onset of epigenetic silencing in rice harboring a multi-copy transgene. Plant J. 14:129135.

Lapidot, M., Gafny, R., Ding, B., Wolf, S., Lucas, W. J., and Beachy, R. N. 1993. A dysfunctional movement protein of Tobacco mosaic virus that partially modifies the plasmodesmata and limits virus spread in transgenic plants. Plant J. 4:959-970.

Lindbo. J. A., and Dougherty, W. G. 1992. Untranslatable transcripts of the Tobacco etch virus coat protein gene sequence can interfere with Tobacco etch virus replication in transgenic plants and protoplasts. Virology 189:725-733.

Lomonossoff, G. P. 1995. Pathogen-derived resistance to plant viruses. Annu. Rev. Phytopathol. 33:323-343.

MacFarlane, S. A., and Davies, J. W. 1992. Plants transformed with a region of the 201-kilodalton replicase gene from Pea early browning virus RNA1 are resistant to virus infection. Proc. Natl. Acad. Sci. USA 89:5829-5833.

MacFarlane, S. A., Taylor, S. C., King, D. I., Hughes, G., and Davies, J. W. 1989. Pea early browning virus RNA1 encodes four polypeptides including a putative zinc-finger protein. Nucleic Acids Res. 17:22452259.

Marano, M. R., and Baulcombe, D. 1998. Pathogen-derived resistance targeted against the negative strand RNA of Tobacco mosaic virus: RNA strand-specific gene silencing? Plant J. 13:537-546.

Mueller, E., Gilbert, J., Davenport, G., Brigneti, G., and Baulcombe, D. C. 1995. Homology-dependent resistance: Transgenic virus resistance in plants related to homology-dependent gene silencing. Plant J. 7:1001-1013

Murashige, T., and Skoog, F. 1962. A revised medium for rapid growth and bioassays with tobacco tissue cultures. Physiol. Plant 15:437-497

Powell-Abel, P., Nelson, R. S., De, B., Hoffmann, N., Rogers, S. G., Fraley, R. T., and Beachy, R. N. 1986. Delay of disease development in transgenic plants that express the Tobacco mosaic virus coat protein gene. Science 232:738-743.

Robinson, D. J., and Harrison, B. D. 1985. Evidence that Broad bean yellow band virus is a new serotype of Pea early browning virus. J. Gen. Virol. 66:2003-2009.

Rogers, S. G., Klee, H. J., Horsch, R. B., and Fraley, R. T. 1987. Improved vectors for plant transformation: Expression cassette vectors and new selectable markers. Pages 253-277 in: Methods in Enzymology. S. P. Colowick and N. O. Kaplan, eds. Academic Press, New York.

Sambrook, J., Fritsch, E. F., and Maniatis, T. 1989. Molecular Cloning: A Laboratory Manual, Cold Spring Harbor Laboratory, Cold Spring Harbor, NY, U.S.A.

Sanford, J. C., and Johnston, S. A. 1985. The concept of parasite-derived resistance-deriving resistance genes from the parasite's own genome. J. Theor. Biol. 113:395-405.

Sijen, T., Wellink, J., Hiriart, J. B., and Van Kammen, A. 1996. RNAmediated virus resistance: Role of repeated transgenes and delineation of targeted regions. Plant Cell 8:2277-2294.

Smith, H. A., Swaney, S. L., Parks, T. D., Wernsman, E. A., and Dougherty, W. G. 1994. Transgenic plant virus resistance mediated by untranslatable sense RNAs: Expression, regulation and fate of nonessential RNAs. Plant Cell 6:1441-1453.

Stam, M., De Bruin, R., Kenter, S., Van der Hoorn, R. A. L., Van Blokland, R., Mol, J. N. M., and Kooter, J. M. 1997. Posttranscriptional silencing of chalcone synthase in Petunia by inverted transgene repeats. Plant J. 12: 63-82.

Stam, M., Viterbo, A., Mol, J. N. M., and Kooter, J. M. 1998. Positiondependent methylation and transcriptional silencing of transgenes in inverted T-DNA repeats: Implications for post-transcriptional silencing of homologous host genes in plants. Mol. Cell Biol. 18:61656177.

Tenllado, F., and Díaz-Ruíz, J. R. 1999. Complete resistance to pepper mild mottle tobamovirus mediated by viral replicase sequences partially depends on transgene homozygosity and is based on a gene silencing mechanism. Trans. Res. 8:83-93.

Van den Boogaart, T., Lomonossoff, G. P., and Davies, J. W. 1998. Can we explain RNA-mediated virus resistance by homology-dependent gene silencing? Mol. Plant-Microbe Interact. 11: 717-723.

Van der Vlugt, R. A. A., Ruiter, R. K., and Goldbach, R. 1992. Evidence for sense RNA-mediated resistance to PVYN in tobacco plants transformed with the viral coat protein cistron. Plant Mol. Biol. 20:631639. 